\title{
Erratum to "The Short-Term Effect of Online Violent Stimuli on Aggression" [Open Journal of Medical Psychology 5 (2016) 35-42]
}

\author{
Jingjin Tian, Qian Zhang \\ School of Applied Technology, Southwest University, Chongqing, China \\ Email: zhq@swu.edu.cn
}

Received: July 4, 2019

Accepted: July 22, 2019

Published: July 25, 2019

Copyright $\odot 2019$ by author(s) and Scientific Research Publishing Inc. This work is licensed under the Creative Commons Attribution International License (CC BY 4.0).

http://creativecommons.org/licenses/by/4.0/

(c) (i) Open Access
The original online version of this article (Tian, J.J., Zhang, Q., Cao, J. and Rodkin, P. (2016) The Short-Term Effect of Online Violent Stimuli on Aggression. Open Journal of Medical Psychology, 5, 35-42.

http://dx.doi.org/10.4236/ojmp.2016.52005) was published as some results data reported mistakenly. The author wishes to correct the errors to:

\begin{abstract}
The significance of this study was to found whether violent stimuli exposure could escalate the following levels of aggression, in order to better cultivate aggression education among contemporary undergraduates in China. This study mainly tested the effects of violent stimuli on aggression by employing modified Stroop task. A total of 188 undergraduates participated in this study. Results showed that undergraduates exposing to violent stimuli exhibited high levels of aggression, whereas undergraduates who exposure to non-violent stimuli displayed low levels of aggression. Specifically, males, but not females, manifested high levels of aggression after exposure to violent stimuli. However, no significant aggressive personality difference was found in aggression after exposure to violent stimuli.
\end{abstract}

\subsection{Participants}

188 Chinese undergraduates (50\% females) were randomly selected to participate in the study. They ranged in age from 19 to 23 years $(M=21.32, S D=1.52)$,

\subsection{Research Design}

A multi-factorial design was employed to examine the main effect and interac- 
tion among variables. A 2 (Stimuli type: violent, non-violent) $\times 2$ (Gender: male, female $) \times 2$ (Aggressive personality: HAP, LAP) three repeated measures analysis of variance (ANOVA) were conducted, with stimuli type, gender and aggressive personality as the between-group factor, and goal word as the within-group factor. Stimuli type was the independent variable, and aggression was the dependent variable.

\section{Results}

In this study, we use RT to aggressive words as a dependent variable. A three-way analysis of variance (ANOVAs) was performed to examine the main effect of stimuli type on aggression. As expected, the significant main effect of stimuli type was found after violent stimuli exposure $[F(1,176)=21.87, P<0.001$; see Table 1], and that participants who exposed to violent stiumuli displayed higher AAS than those who exposed to nonviolent stimuli. Further, a significant stimuli type $\times$ gender interaction was found $[F(1,176)=20.58, P<0.001]$, and further simple effect analysis indicated that AAS of males was significantly smaller when exposing to violent stimuli than when exposing to non-violent stimuli $[F(1,176)$ $=79.02, P<0.01]$, but no significant difference for AAS offemales $[F(1,176)=$ $0.01, P>0.05$; see Table 2)]. However, no significant movie type $\times$ aggressive personality interaction was found $[F(2,176)=1.05, P>0.05$; see Table 1$]$.

Table 1. ANOVA for AAS among research variables.

\begin{tabular}{lll}
\hline Variables & Mean Square & $\mathrm{F}$ \\
\hline Stimuli type & $119,388.24$ & $21.87^{* * *}$ \\
Stimuli type $\times$ Gender & $112,329.49$ & $20.58^{* * *}$ \\
Stimuli type $\times$ aggressive personality & 5739.42 & 1.05 \\
\hline
\end{tabular}

Note. ${ }^{* *} \mathrm{P}<0.001$.

Table 2. Post hoc test of AAS difference for males and females.

\begin{tabular}{llll}
\hline Gender & $\begin{array}{l}\text { Violent } \\
\text { M (SD) }\end{array}$ & $\begin{array}{l}\text { Non-violent } \\
\text { M (SD) }\end{array}$ & F \\
\hline Males & $777.64(11.15)$ & $625.44(12.99)$ & $79.02^{* * *}$ \\
Females & $592.46(26.17)$ & $590.14(10.67)$ & 0.01 \\
\hline
\end{tabular}

Note. ${ }^{* *} \mathrm{P}<0.001$.

\section{Discussion}

\subsection{Violent Stimuli Exposure Could Significantly Elevate Aggression}

Overall, we found that violent stimuli significantly activated aggression among undergraduates. This result supported our first hypothesis, and it was correspondent with the previous study [11]. Some experts assumed contextual factors were responsible for aggressive behavior after viewing violent movies [2]. 


\subsection{Violent Stimuli Exposure Did Not Induce Significant} Differences in Aggressive Personality

In this study, there was no significant difference in aggressive personality after viewing violent stimuli. This result was not in agreement with hypothesis 3 . In the process of adaptability on campus, aggressive paersonality might not the real reason to cause students show more aggression. Hence, educators can ignore the aggressive personality of students after viewing violent stimuli. The aggressive personality might not be a necessary individual factor to impact levels of aggression among Chinese undergraduates after exposing to violent pictures. 